\title{
Tibial and femoral osteotomies in varus deformities - radiological and clinical outcome
}

\author{
Julian Fürmetz ${ }^{1 *}$, Sven Patzler ${ }^{1}$, Florian Wolf ${ }^{1}$, Nikolaus Degen ${ }^{1}$, Wolf Christian Prall ${ }^{2,3}$, Chris Soo ${ }^{4,5}$, \\ Wolfgang Böcker ${ }^{2}$ and Peter Helmut Thaller ${ }^{1}$
}

\begin{abstract}
Background: Varus deformities of the knee are frequently corrected by osteotomies, which should be performed at the level of origin. But in contrast to high tibial osteotomies (HTO), little data exists for distal femoral osteotomies (DFO).

This study evaluates radiological and clinical outcomes after valgisation osteotomies in the proximal tibia and distal femur.

Methods: We used an observational cohort study design and prospectively performed preoperative long standing radiographs (LSR), lateral $x$-rays and clinical questionnaires (SF-36, Lysholm score, VAS). Postoperative LSR and lateral $x$-rays were obtained on average 18 months postoperative and postoperative clinical questionnaires at final visit (mean follow up 46 months). A subgroup analysis of the different surgical techniques (oHTO vs. CDFO) was performed, with regards to radiological and clinical outcomes.

Results: Finally 28 osteotomies with medial tibial opening (oHTO) or lateral femoral closing (CDFO) wedge osteotomies in 25 consecutive patients (mean age 40 years) were identified. There were 17 tibal and 11 femoral procedures. All osteotomies were performed at the origin of deformity, which was of different etiology. The average deviation of the final HKA compared to the preoperative planning was $2.4^{\circ} \pm 0.4^{\circ}$. Overall, there was a significant improvement in all clinical scores (SF-36: 61.8 to 79.4, $p<0.001$; Lysholm-score: 72.7 to 90.4, $p<0.001$; VAS: 3 to 1, $p<0.001$ ). There was no significant correlation between surgical accuracy and outcome scores.

Conclusion: Valgisation osteotomies lead to a significant improvement in all clinical scores with the demonstrated treatment protocol. An appreciable proportion of varus deformities are of femoral origin. Since cDFO provides comparable radiological and clinical results as oHTO, this is an important treatment option for varus deformities of femoral origin.
\end{abstract}

Keywords: Osteotomies, Distal femoral osteotomy, DFO, High Tibial osteotomy, HTO, Valgisation, Realignment, Varus deformities, Medial osteoarthritis

\footnotetext{
* Correspondence: Julian.Fuermetz@med.uni-muenchen.de

13D-Surgery, Department of General, Trauma and Reconstructive Surgery, University of Munich LMU, Nußbaumstraße 20, 80336 München, Germany

Full list of author information is available at the end of the article
}

(c) The Author(s). 2020 Open Access This article is licensed under a Creative Commons Attribution 4.0 International License, which permits use, sharing, adaptation, distribution and reproduction in any medium or format, as long as you give appropriate credit to the original author(s) and the source, provide a link to the Creative Commons licence, and indicate if changes were made. The images or other third party material in this article are included in the article's Creative Commons licence, unless indicated otherwise in a credit line to the material. If material is not included in the article's Creative Commons licence and your intended use is not permitted by statutory regulation or exceeds the permitted use, you will need to obtain permission directly from the copyright holder. To view a copy of this licence, visit http://creativecommons.org/licenses/by/4.0/. The Creative Commons Public Domain Dedication waiver (http://creativecommons.org/publicdomain/zero/1.0/) applies to the data made available in this article, unless otherwise stated in a credit line to the data. 


\section{Background}

Varus malalignment has been identified as a risk factor for the incidence and progression of medial osteoarthritis (OA) [1]. Deformity correction with osteotomies near the knee joint is therefore an important therapeutic intervention, which may prevent or delay the need for joint replacement even in cases of severe cartilage damage independent of patient age [2]. This is especially relevant in younger patients, as lifetime risk of revision surgery after knee joint replacements increases dramatically within this patient group [3].

In varus deformities, osteotomies were usually performed in the tibia, with valgus deformities predominantly treated with femoral procedures. However, it has become common practice to perform a deformity analysis using a long standing radiograph (LSR) to determine the origin of deformity prior to surgery $[4,5]$, since varus deformities can be localized either in the tibia or in the femur [6-8]. In the case of femoral malalignment, a high tibial osteotomy (HTO) results in a pathological oblique knee joint line with increased shear forces and vice versa in the case of a tibial malalignment and femoral correction [9]. Clinical and biomechanical studies indicate that if the postoperative knee joint line is not physiologically aligned, this leads to a poor result $[7,10,11]$.

In contrast to the HTO, very little clinical data exist on lateral distal femoral osteotomies (DFO) in cases of varus deformities. At the distal femur, a closed wedge procedure is recommended due to the frequent instability in femoral open wedge osteotomies [12]. There exist only 2 studies reporting on lateral distal closing wedge femoral osteotomies, covering a total of only 19 cases $[6,8]$.

For the first time, this study evaluates radiological and clinical outcomes in valgisating femoral and tibial osteotomies.

\section{Methods}

\section{Patients}

Patients with symptomatic varus deformity treated with deformity correction (oHTO or cDFO) close to the knee joint were included in the study. Excluded were patients requiring simultaneous multilevel osteotomies or those with incomplete follow up.

In total, from 2009 to 2016, there were 28 osteotomies on 25 consecutive patients with varus deformities. The etiology was heterogenous: 9 congenital, 14 growthrelated and 5 post-traumatic deformities. The demographic characteristics of patients including the BMI are presented in Table 1. Institutional review board approval was obtained for the study (EC-Nr.: 16-008). All involved patients gave their informed consent statement prior to the study inclusion.

\section{Standardised radiological and clinical assessment}

Radiographic analysis of the pre- and postoperative LSR included the following parameters: mechanical axis deviation (MAD), hip knee angle (HKA), medial proximal tibial angle (MPTA), mechanical lateral distal femoral angle (mLDFA), joint line convergence angle (JLCA), patella height (CatonDeschamps index), tibial slope, and posterior distal femoral angle (PDFA), according to the definitions by Paley [13]. For a better comparability to previous reports, we included the HKA. But in our daily clinical practice, joint angles, JLCA and MAD are the most important parameters for both our preoperative planning process and post-operative evaluation of the final result (Fig.1).

\section{Preoperative}

Preoperative planning was performed using the End Point First (EPF) planning method on long standing radiographs $[14,15]$. Depending on the origin of deformity, the osteotomy site was chosen and lateral $x$-ray images of femur and/or tibia were added. In femoral malalignment $\left(\mathrm{mLDFA}>90^{\circ}\right)$, patients were treated with a lateral closed wedge distal femoral osteotomy $(n=11$, $39 \%)$. In 17 knee joints (61\%), analysis revealed a tibial deformity (MPTA $<85^{\circ}$ ), and medial open wedge high tibial osteotomy (oHTO) was performed.

Two patients underwent two-stage bifocal osteotomies. If possible, joint angles did not exceed normal values in preoperative planning $\left(\mathrm{MPTA} \leq 90^{\circ}, \operatorname{mLDFA} \geq 85^{\circ}\right)$. However,

Table 1 Demographic characteristics of patients

\begin{tabular}{|c|c|c|}
\hline & oHTO & cDFO \\
\hline Number of osteotomies (n (\%)) & $17(61 \%)$ & $11(39 \%)$ \\
\hline Mean age at surgery (years $\pm \mathrm{SD}($ min-max)) & $37 \pm 3(18-61)$ & $45 \pm 4(23-64)$ \\
\hline $\operatorname{Sex}(m: f)$ & $9: 8$ & $9: 2$ \\
\hline Mean BMI $\left(\mathrm{kg} / \mathrm{m}^{2}\right)$ at surgery $( \pm \mathrm{SD}(\min -\mathrm{max}))$ & $25 \pm 1(17-30)$ & $29 \pm 2(24-46)$ \\
\hline $\mathrm{BMl}<18,5 \mathrm{~kg} / \mathrm{m}^{2}(\mathrm{n})$ & 1 & 0 \\
\hline BMI $18,5-24,9$ kg/m² (n) & 9 & 3 \\
\hline $\mathrm{BMI}>25-29,9 \mathrm{~kg} / \mathrm{m}^{2}(\mathrm{n})$ & 7 & 6 \\
\hline $\mathrm{BMI}>30 \mathrm{~kg} / \mathrm{m}^{2}(\mathrm{n}(\%))$ & 0 & 2 \\
\hline Mean follow-up (months $( \pm$ SD)) & $41 \pm 6$ & $55 \pm 8$ \\
\hline
\end{tabular}




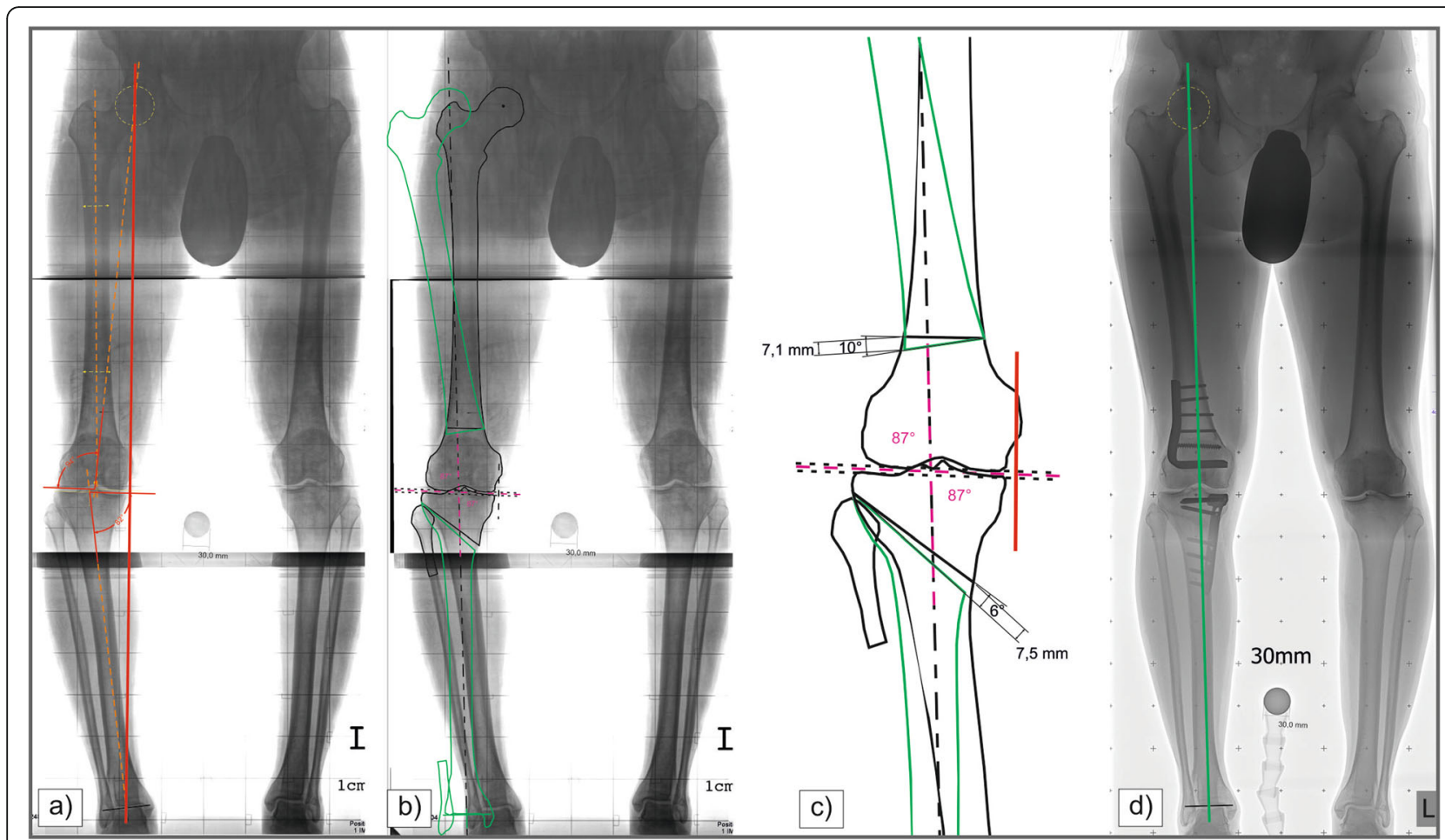

Fig. 1 Two-staged femoral and tibial deformity correction in varus malalignment: a preoperative LSR with mechanical axis (red line), MPTA 82 and $\mathrm{mLDFA} 94^{\circ} ; \mathbf{b}$ and $\mathbf{c}$ end point first planning with the new mechanical axis (black dotted line), $87^{\circ}$ joint angles and preoperative mechanical axis (red short line); $\mathbf{d}$ final result after CDFO and oHTO with the new mechanical axis (green line)

in order to avoid a second intervention, some patients required a planned overcorrection, which were intended not to exceed 93 or 82 degrees respectively. To assess for functional and clinical status prior to admission, we used the Lysholm score, the, Short-Form-36 Health Survey (SF-36), and the Visual Analog Scale (VAS).

\section{EPF - method}

The EPF method starts with a malalignment test of the lower limb $[4,13]$. The centers of the hip and ankle are determined, and a line is then drawn from the center of the hip joint to the center of the ankle joint. Next, tibial and femoral knee joint lines are drawn and the lateral distal femoral angle and medial proximal tibial angle are measured. In tibial deformities the new mechanical axis starts from the hip center and in femoral deformities from the ankle center and runs between the intercondylar tubercles. The aiming point of the new mechanical axis is between the medial and lateral intercondylar tubercle depending on cartilage and meniscal tears. After the osteotomy is located on paper or on a digital platform, the proximal part of the femur/distal part of the tibia is moved to the final location of the femoral head/ankle center located on the mechanical axis. In bifocal deformities a vertical line is drawn such that it forms an 87-degree lateral angle with the distal femoral joint line. This will subsequently be the new mechanical axis of the entire leg (Fig. 1).

\section{Intraoperative}

The same surgeon operated on all the patients. Intraoperative alignment control was performed with the $\mathrm{x}$-ray grid, a $3 \mathrm{~mm}$ thin phenolic resin hard paper plate with intersected distinguishable radiopaque reference lines for determination of the mechanical axis. At the beginning of the procedure, meniscal and cartilage lesions were evaluated with arthroscopy. There were 4 meniscal partial resections and no cartilage intervention. Only TomoFix (Synthes, Oberdorf, Switzerland) plates were used as implants for the oHTO and the operative technique was similar to Staubli et al. with biplanar cutting technique [16]. We used a $95^{\circ}$ blade plate (Synthes, Oberdorf, Switzerland) for femoral fixation. Operative technique for cDFO was similar to Lobenhoffer et al. [12].

\section{Postoperative}

Postoperative standard treatment was partial weight bearing $(20 \mathrm{~kg})$ for 6 weeks and regular physiotherapy.

On average, final radiological examination took place 6 months after implant removal, including LSR and lateral $x$ ray, which was generally 18 months postoperative. Mean follow up for clinical examination including questionnaires 
(Lysholm score, SF-36, VAS) was 47 months postoperatively (Tab. 2), with a minimum of 24 months.

\section{Statistics}

As test of significance, a two-sided Wilcoxon test for dependent groups was performed (SPSS version 25, SPSS Inc., Chicago/Illinois, USA) to evaluate changes in radiological and clinical parameters before and after surgery. Subgroup differences (oHTO vs. cDFO) were calculated with the Mann-Whitney U test.

\section{Results}

\section{Radiological results}

The average deviation of the final HKA compared to the preoperative planning was $2.4^{\circ} \pm 0.4^{\circ}$.

The preoperative HKA was on average $-7.4^{\circ} \pm 0.8$ in the oHTO group and $-7.0^{\circ}(\mathrm{SD} \pm 1.1)$ in the cDFO group, while the average amount of final correction was slightly higher in the oHTO group $\left(7.3 \pm 0.9^{\circ}\right)$ versus the cDFO group $\left(6.2 \pm 1.6^{\circ}\right)$ (final average HKA was -0.1 vs. -0.7) (Fig. 2). The oHTO group had a slightly more precise correction result, with an absolute mean deviation of $2.2^{\circ} \pm 0.5$ from preoperative planning, compared to the cDFO group with $2.6^{\circ} \mathrm{SD} \pm 0.7$. Accordingly, a deviation of less than $\pm 3^{\circ}$ was observed more frequently in the oHTO group after surgery (14 cases / 82\%) than in the cDFO group (7 cases, 64\%).

MAD changed from -26.8 to $-0.1 \mathrm{~mm}$ on average in the oHTO group $(p<0.001)$, and slightly less in the cDFO group with -24.4 to $-3.6 \mathrm{~mm}(p=0.004)$. Differences between groups were not significant. Maximum preoperative MAD was $-44.4 \mathrm{~mm}$ in the oHTO group and $-49.8 \mathrm{~mm}$ in the $\mathrm{cDFO}$ group.

In tibial procedures, mean MPTA changed from $83.4^{\circ} \pm$ 0.7 to $90.2^{\circ} \pm 0.9$ postoperatively $(p<0.001)$. Average preoperative planning of MPTA was $90.5^{\circ} \pm 0.6^{\circ}$ (min. $85.6^{\circ}-$ $\max .93 .0^{\circ}$ ), and the final absolute deviation from preoperative planning was $1.7 \pm 0.4^{\circ}\left(\min .0 .2^{\circ}-\max .5 .9^{\circ}\right)$. In 6 of 7 patients with MPTA $\left(>90^{\circ}\right)$, planning of minor overcorrection was intended to address severe medial cartilage damage and to avoid bifocal osteotomies.
Due to the $\mathrm{cDFO}$, the preoperative mLDFA decreased from an average of $92.1^{\circ} \pm 1.0$ to $86.0^{\circ} \pm 0.7(p=0.003)$. The preoperative planning of mLDFA was $85.5 \pm 0.6^{\circ}$ (min. $\left.83.4^{\circ}-\max .89 .5^{\circ}\right)$ and the final absolute deviation from planning was $2.3 \pm 0.4^{\circ}\left(\min .0 .3^{\circ}-\max .4 .6^{\circ}\right)$. We identified 3 patients with overcorrected mLDFA $\left(<85^{\circ}\right)$, of which all had severe medial cartilage damage and overcorrection was planned.

In the oHTO group, the JLCA decreased in average from $-2.1^{\circ} \pm 0.4$ to $-1.6^{\circ} \pm 0.3$ and in the $\mathrm{cDFO}$ group from $-2.3^{\circ} \pm 0.5$ to $-1.9^{\circ} \pm 0.4$. In both groups, leg length changed by $0.6 \mathrm{~mm}$ per degree of correction in MPTA / mLDFA. The oHTO increased tibial slope by an average of $0.8^{\circ} \pm 0.8$ from $8.9^{\circ}$ to $9.7^{\circ}$ postoperatively. In contrast, the cDFO influenced the PDFA more clearly (by $4.9^{\circ} \pm$ 2.6) with an average preoperative PDFA of $83.8^{\circ}$ to $88.8^{\circ}$ postoperatively. A significant height reduction of the patella was observed only in the oHTO group (Caton Deschamps from $0.84 \pm 0.02$ to $0.74 \pm 0.02 ; p<0.05$ ). No relevant changes were observed in the cDFO group (Caton Deschamps index from $0.79 \pm 0.05$ to $0.80 \pm 0.08$ ).

\section{Clinical results}

All clinical scores showed significant improvement at the final examination (mean follow up 47 months). The SF-36 quality of life score showed almost identical results for both groups, with the oHTO group achieving a significant improvement from 61.3 to 78.7 points $(p<$ 0.001 ), and the cDFO group increasing from 62.6 to 80.5 $(p=0.005)$ (Fig. 3).

The Lysholm Score improved significantly in the oHTO group by an average of 16.9 points from 73.6 to 90.5 ( $p=$ 0.001 ). The cDFO group also achieved a similar result, with an average improvement of 19.6 points from 71.6 to $90.2(p=0.005)$ (Fig. 3).

The VAS improved in the cDFO group with an average of 2.5 points $(\mathrm{SD} \pm 0.7 ; p=0.003)$ and in the oHTO group with 1.9 points $(\mathrm{SD} \pm 0.5$ points; $p=0.001)$. In total, $64 \%$ of all patients reported complete absence of pain at the final examination.

Table 2 describes the results of the clinical scores for both groups pre- and postoperatively, distinguishing between

Table 2 Clinical results of corrections within and beyond the normal range of $85-90^{\circ}$ MPTA / mLDFA

\begin{tabular}{|c|c|c|c|c|c|c|}
\hline & & \multirow[b]{2}{*}{ n (\%) } & \multicolumn{2}{|l|}{ SF-36 } & \multicolumn{2}{|l|}{ Lysholm-Score } \\
\hline & & & preoperative & postoperative & preoperative & postoperative \\
\hline \multirow[t]{2}{*}{ OHTO } & $\begin{array}{l}\text { normal } \\
\left(\text { MPTA }<90^{\circ}\right)\end{array}$ & $10(56 \%)$ & 63 & 79 & 76 & 94 \\
\hline & $\begin{array}{l}\text { overcorrection } \\
\left(\text { MPTA }>90^{\circ}\right)\end{array}$ & $7(44 \%)$ & 57 & 77 & 69 & 84 \\
\hline \multirow[t]{2}{*}{ cDFO } & $\begin{array}{l}\text { normal } \\
\left(m L D F A>85^{\circ}\right)\end{array}$ & $\begin{array}{l}8 \\
(73 \%)\end{array}$ & 64 & 83 & 76 & 97 \\
\hline & $\begin{array}{l}\text { overcorrection } \\
\left(m L D F A<85^{\circ}\right)\end{array}$ & $3(17 \%)$ & 57 & 74 & 59 & 71 \\
\hline
\end{tabular}




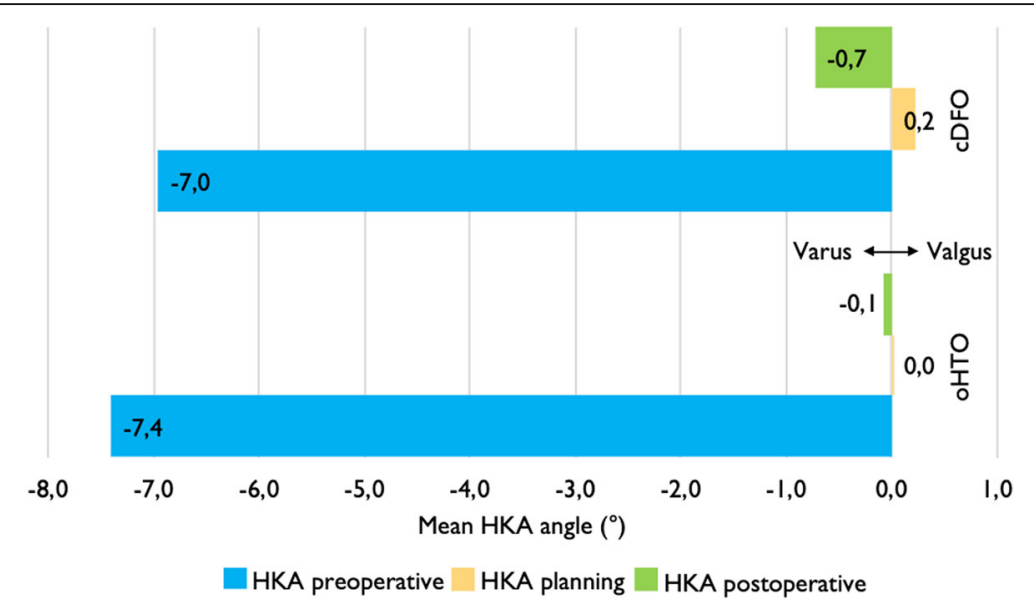

Fig. 2 Mean preoperative $H K A^{\circ}$ (blue) of both subgroups, preoperative planning of $H K A^{\circ}$ (yellow) and final $H K A^{\circ}$ (green)

overcorrections in MPTA/mLDFA compared to corrections within the normal range. It can be seen that the overcorrections have lower preoperative initial values and reach lower postoperative values, most likely reflecting a more severe cartilage damage in these patients.

\section{Clinical course and complications}

There were no relevant differences in hospital stay, blood loss or surgery time. One occurrence of delayed bone formation in the oHTO group was successfully treated with autologous bone grafting.

\section{Discussion}

This study evaluates radiological and clinical midterm outcome of re-alignment procedures in case of varus deformtities. The importance of comparing preoperative planning with actual postoperative alignment and the associated clinical outcome is emphasised. This allows to calculate the accuracy of the procedure with a mean deviation of $2.2^{\circ}$ in the oHTO and $2.6^{\circ}$ in dhe cDFO group in this study cohort.

\section{Mechanical axis and joint angles}

The ideal degree of correction in cases of varus malalignment has been intensively discussed over many years. Several authors have identified a postoperative HKA of $3-5^{\circ}$ valgus or a mechanical axis at $62-66 \%$ of the tibial width as optimal in medial OA [17-20]. Recently studies consider the extent of medial chondromalacia and perform an individually adjusted correction with a more moderate targeted range of valgus (HKA $1.7-5^{\circ}$ or $50-65 \%$ of the total tibial plateau width), while avoiding overcorrection $[4,21]$. A knee joint arthroscopy is recommended in the same session, for addressing intraoperative pathologies and fine-

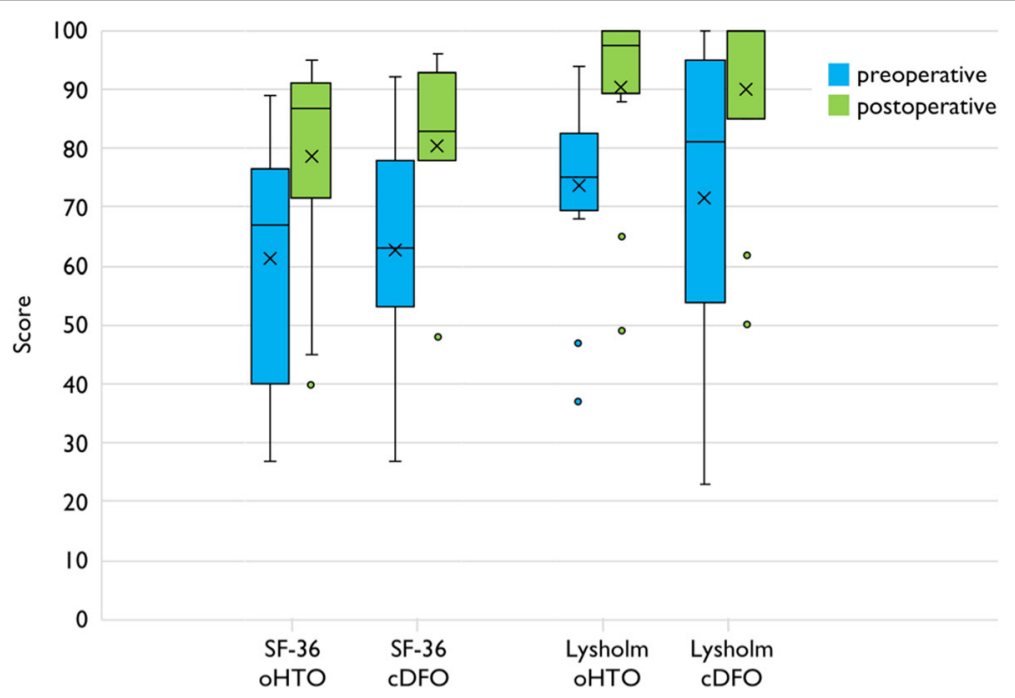

Fig. 3 Boxplot of pre- and postoperative results of the SF- 36 and Lysholm-Score of both subgroups; $x$ indicating the mean value 
tuning of correction, depending on the type and extent of intraarticular damage [22]. Our approach corresponds to this and the average HKA and MAD of our patients indicate a postoperatively centered, and not a new, lateralised, mechanical axis. This is explained by the different etiologies in our study group, including younger patients without structural damage but with medial knee pain. For these patients the aiming point of the new mechanical axis is the medial intercondylar tubercle and for patient with grade IV medial cartilage degeneration (outerbridge classification) the lateral one.

Besides the new mechanical axis, joint angles are most important in preoperative planning. Overcorrection of the joint angles results in an oblique knee joint line with increased shear forces and poorer clinical outcome $[7,10]$.

But an overcorrection of MPTA $\left(>90^{\circ}\right)$ or mLDFA (< $85^{\circ}$ ) was intended and performed in some of our patients with relevant OA. These patients had lower preoperative and postoperative values in all clinical scores. But still, the improvement of the scores was similar (Tab. 2). Therefore, it cannot be concluded from our data that overcorrections must be avoided and double level osteotomies should be performed, but other clinical and experimental data indicate this very strongly $[7,9,10,23,24]$. The maximum overcorrection that can be tolerated in femoral and tibial osteotomies should be examined more closely in further studies.

\section{Accuracy}

Several HTO studies agree with $\mathrm{a} \pm 3^{\circ}$ deviation from planning as an acceptable range [25-28]. Reported results are very variable with 23 to $92 \%$ being in the defined target range [25-28]. 82\% of our HTO-patients were within this range, so accuracy can be rated as good, but leaving room for improvement. To our knowledge, no results are available regarding accuracy of cDFO in literature. In our study, 64\% (7 of 11) of the patients were within the $\pm 3^{\circ}$ limit of deviation with regards to preoperative planning. This is explained by the technically demanding closed wedge osteotomy, since the surgeon must rely on the accuracy of the bone resection, and intraoperative readjustment is only possible to a limited extent $[6,12]$. Lateral inaccuracy of DFO could be produced by the same reason and due to the tension of the gastrocnemius muscle on the distal femur. The tibial slope influences the coronal alignment in long standing radiographs [29]. Sagittal changes in the distal femoral group may have influenced the coronal alignment and could count for some degree of inaccuracy.

There are various approaches to improve the accuracy of osteotomies. Simple and helpful in HTO is careful gap measurement [28]. Very promising results have recently been published by a single research group using patientspecific cutting guides in oHTO and oDFO [30,31]. Another research group published improved results in medial
cDFO for varization with 3D-printed patient-specific cutting guides [32]. This technique appears to be a promising option for both closing and opening wedge osteotomies to improve accuracy in the future, but there are still unsolved issues such as the complex and costly preoperative planning and printing process or the need for extensive bone exposure.

\section{Clinical outcome}

Several authors report an improvement of clinical scores for up to 5 years postoperatively after HTO. The average postoperative Lysholm score is reported to range between 69 and 96 points and the mean SF-36 between 73 and 89 points [33-38]. Referring to those reports, the clinical results of our oHTO patients are within the upper range. Only the study by van der Woude et al. investigated the postoperative clinical outcome after a cDFO so far and reported a Lysholm score of 73 points and a pain level of 3 (VAS) [6]. In comparison, the patients in our cDFO group showed a 17-point higher Lysholm score and a 2-point lower postoperative pain level. Survival rates of the different treatment options diverge noticeably after a follow-up of 10 years. 5 -year survival for oHTO was $90-99 \%$, and was $94 \%$ for cDFO [6, 39]. After 10 years, the oHTO survival rate decreases to 64-92\% [40]. A follow-up of more than 5 years for the cDFO is currently not described in literature.

\section{Limitations}

Limitations of this study are the heterogeneous study population and the low case number for femoral and tibial osteotomies. The expected number of cases within this cohort and the mean values and standard deviations in accuracy and clinical outcome parameters in previous studies were too small for a prospective power analysis. Additionally, long-term information about clinical function or survival rates is missing.

High-volume studies from national or international databases with a focus on accuracy and resulting clinical function are necessary, because previous studies suggest that single clinical centers do not have sufficiently high case numbers to answer these questions. In our study group, over one third of the patients presented with varus malalignment of the distal femur and therefore were treated by distal femoral osteotomy. Reviewing the literature, distal femoral osteotomies are rarely described, which may reflect a high number of HTOs applied in cases with deformity at the distal femur. Similarly, in valgus deformities, the dogma that valgus = femur could already be disproved [40]. This reinforces our conviction that radiological evaluation (preoperative situation, planning and final result) must always be taken into account when evaluating the clinical results of osteotomies. 


\section{Conclusion}

Our results indicate that an appreciable proportion of varus deformities are of femoral origin and that $\mathrm{cDFO}$ provides comparable radiological and clinical results as oHTO. Through appropriate indication and patient selection, both kinds of valgisation osteotomies close to the knee joint can provide improvements in clinical function, pain level and quality of life. These jointpreserving interventions thus represent a valuable treatment option in varus deformities.

\section{Abbreviations \\ OA: Osteoarthritis; LSR: Long Standing Radiograph; HTO: High Tibial Osteotomy; DFO: Distal Femoral Osteotomy; BMI: Body Mass Index; MPTA: Medial proximal tibial angle; mLDFA: Mechanical lateral distal femoral angle; HKA: Hip knee angle; SF-36: Visual Analog Scale, Short-Form-36 Health Survey; MAD: Mechanical axis deviation; PDFA: Joint Line Convergence Angle, posterior distal femoral angle}

\section{Acknowledgements}

None.

\section{Authors' contributions}

FJ, PS, and TPH conceived and planned the study. FJ, PS, and TPH carried out the data acquisition. FJ, PS, WF, DN, PC, and TPH contributed to the interpretation of the results. FJ and SC took the lead in writing the manuscript. BW corrected the manuscript and gave directional input throughout the study. All authors provided critical feedback and helped shape the research, analysis and manuscript. The author(s) read and approved the final manuscript.

\section{Funding}

This research did not receive any specific grant from funding agencies in the public, commercial, or not-for-profit sectors.

\section{Availability of data and materials}

The anonymised results of the radiological measurements and the clinical questionnaires are attached in the form of an Excel spreadsheet.

\section{Ethics approval and consent to participate}

Institutional review board approval of the Ethics Committee of the Faculty of Medicine at LMU Munich was obtained for the study (EC-Nr.: 16-008). All involved patients gave their written informed consent statement prior to the study inclusion.

\section{Consent for publication}

All involved patients gave their written informed consent to publication.

\section{Competing interests}

There are no competing interests.

\section{Author details}

13D-Surgery, Department of General, Trauma and Reconstructive Surgery, University of Munich LMU, Nußbaumstraße 20, 80336 München, Germany. ${ }^{2}$ Department of General, Trauma and Reconstructive Surgery, University of Munich LMU, Munich, Germany. ${ }^{3}$ Paracelsus Medical University PMU, Salzburg, Austria. ${ }^{4}$ Faculty of Health Sciences and Medicine, Bond University, Gold Coast, QLD, Australia. ${ }^{5}$ School of Medicine, Griffith University, QLD, Gold Coast, Australia.

Received: 22 August 2019 Accepted: 24 March 2020

Published online: 31 March 2020

\section{References}

1. Sharma L, Chmiel JS, Almagor O, Felson D, Guermazi A, Roemer F, et al. The role of varus and valgus alignment in the initial development of knee cartilage damage by MRI: the MOST study. Ann Rheum Dis. 2013;72:235-40.
2. Floerkemeier S, Staubli AE, Schroeter S, Goldhahn S, Lobenhoffer P. Outcome after high tibial open-wedge osteotomy: a retrospective evaluation of 533 patients. Knee Surg Sports Traumatol Arthrosc Off J ESSKA. 2013;21:170-80.

3. Bayliss LE, Culliford D, Monk AP, Glyn-Jones S, Prieto-Alhambra D, Judge A, et al. The effect of patient age at intervention on risk of implant revision after total replacement of the hip or knee: a population-based cohort study. Lancet Lond Engl. 2017;389:1424-30.

4. Paley D, Tetsworth K. Mechanical axis deviation of the lower limbs: preoperative planning of uniapical angular deformities of the tibia or femur. Clin Orthop. 1992:280:48-64.

5. Thaller PH, Baumgart R, Burghardt R, Knuellig S, Buerklein D, Mutschler W. Digital imaging in lower limb bone deformities-standards and new perspectives. In: Elsevier International Congress Series 1281; 2005. p. 154-8.

6. van der Woude JAD, Spruijt S, van Ginneken BTJ, van Heerwaarden RJ. Distal femoral valgus osteotomy: bone healing time in single plane and biplanar technique. Strateg Trauma Limb Reconstr. 2016;11:177-86.

7. Babis GC, An K-N, Chao EYS, Rand JA, Sim FH. Double level osteotomy of the knee: a method to retain joint-line obliquity. Clinical results. J Bone Joint Surg Am. 2002;84-A:1380-8.

8. Bagherifard A, Jabalameli M, Hadi HA, Rahbar M, Mokhtari T, Yahyazadeh $H_{\text {, }}$ et al. The results of biplanar distal femoral osteotomy; a case series study. Arch Bone Jt Surg. 2015;3:35-8

9. Saragaglia D, Mercier N, Colle P-E. Computer-assisted osteotomies for genu varum deformity: which osteotomy for which varus? Int Orthop. 2010;34: 185-90.

10. Terauchi M, Shirakura K, Katayama M, Higuchi H, Takagishi K, Kimura M. Varus inclination of the distal femur and high tibial osteotomy. J Bone Joint Surg Br. 2002;84:223-6.

11. Amis AA. Biomechanics of high tibial osteotomy. Knee Surg Sports Traumatol Arthrosc Off J ESSKA. 2013;21:197-205.

12. Lobenhoffer P, Van Heerwaarden R. Osteotomies around the knee: indications-planning-surgical techniques using plate fixators. New York: Georg Thieme Verlag; 2009. http://kcl.eblib.com/patron/FullRecord.aspx?p= 1250532. Accessed 21 Sep 2018.

13. Paley D, Herzenberg J, editors. Principles of deformity correction. Berlin: Springer; 2005.

14. Thaller PH, Wolf F, Kucukkaya M. Surgical Techniques for Lengthening and Deformity Correction of the Tibia With Lengthening Nails. Tech Orthop. 2014:29:150-7.

15. Kucukkaya M, Sokucu S, Thaller PH. Surgical techniques for lengthening and deformity correction of the femur with lengthening nails. Tech Orthop. 2015:30:183-8.

16. Staubli AE, De Simoni C, Babst R, Lobenhoffer P. TomoFix: a new LCPconcept for open wedge osteotomy of the medial proximal tibia--early results in 92 cases. Injury. 2003;34(Suppl 2):B55-62.

17. Hernigou P, Medevielle D, Debeyre J, Goutallier D. Proximal tibial osteotomy for osteoarthritis with varus deformity. A ten to thirteen-year follow-up study. J Bone Joint Surg Am. 1987:69:332-54.

18. Miniaci A, Ballmer FT, Ballmer PM, Jakob RP. Proximal tibial osteotomy. A new fixation device. Clin Orthop. 1989;246:250-9.

19. Dugdale TW, Noyes FR, Styer D. Preoperative planning for high tibial osteotomy. The effect of lateral tibiofemoral separation and tibiofemoral length. Clin Orthop. 1992;274:248-64.

20. Fujisawa $Y$, Masuhara K, Shiomi S. The effect of high tibial osteotomy on osteoarthritis of the knee. An arthroscopic study of 54 knee joints. Orthop Clin North Am. 1979;10:585-608.

21. Schröter S, Ihle C, Mueller J, Lobenhoffer P, Stöckle U, van Heerwaarden R. Digital planning of high tibial osteotomy. Interrater reliability by using two different software. Knee Surg Sports Traumatol Arthrosc Off J ESSKA. 2013; 21:189-96.

22. Müller M, Strecker W. Arthroscopy prior to osteotomy around the knee? Arch Orthop Trauma Surg. 2008;128:1217-21.

23. Nakayama H, Iseki T, Kanto R, Kambara S, Kanto M, Yoshiya S, et al. Physiologic knee joint alignment and orientation can be restored by the minimally invasive double level osteotomy for osteoarthritic knees with severe varus deformity. Knee Surg Sports Traumatol Arthrosc. 2020;28:740-50.

24. Nakayama H, Schröter S, Yamamoto C, Iseki T, Kanto R, Kurosaka K, et al. Large correction in opening wedge high tibial osteotomy with resultant joint-line obliquity induces excessive shear stress on the articular cartilage. Knee Surg Sports Traumatol Arthrosc Off J ESSKA. 2018;26:1873-8. 
25. Brouwer RW, Bierma-Zeinstra SMA, Van Raaij TM, Verhaar JAN. Osteotomy for medial compartment arthritis of the knee using a closing wedge or an opening wedge controlled by a Puddu plate a one-year randomised, controlled study. J Bone Joint Surg Br. 2006:88:1454-9.

26. Iorio R, Pagnottelli M, Vadalà A, Giannetti S, Di Sette P, Papandrea P, et al. Open-wedge high tibial osteotomy: comparison between manual and computer-assisted techniques. Knee Surg Sports Traumatol Arthrosc. 2013; 21:113-9.

27. Duivenvoorden T, Brouwer RW, Baan A, Bos PK, Reijman M, Bierma-Zeinstra SMA, et al. Comparison of closing-wedge and opening-wedge high Tibial osteotomy for medial compartment osteoarthritis of the knee: a randomized controlled trial with a six-year follow-up. J Bone Jt Surg. 2014; 96:1425-32.

28. Schröter S, Ihle C, Elson DW, Döbele S, Stöckle U, Ateschrang A. Surgical accuracy in high tibial osteotomy: coronal equivalence of computer navigation and gap measurement. Knee Surg Sports Traumatol Arthrosc Off J ESSKA. 2016;24:3410-7.

29. Schwartz AJ, Ravi B, Kransdorf MJ, Clarke HD. Does Tibial slope affect perception of coronal alignment on a standing Anteroposterior radiograph? J Arthroplast. 2017:32:2285-8.

30. Jacquet C, Chan-Yu-Kin J, Sharma A, Argenson J-N, Parratte S, Ollivier M. More accurate correction using "patient-specific" cutting guides in opening wedge distal femur varization osteotomies. Int Orthop. 2019;43:2285-91.

31. Chaouche S, Jacquet C, Fabre-Aubrespy M, Sharma A, Argenson J-N Parratte $S$, et al. Patient-specific cutting guides for open-wedge high tibial osteotomy: safety and accuracy analysis of a hundred patients continuous cohort. Int Orthop. 2019;43:2757-65.

32. Shi J, Lv W, Wang Y, Ma B, Cui W, Liu Z, et al. Three dimensional patientspecific printed cutting guides for closing-wedge distal femoral osteotomy. Int Orthop. 2019;43:619-24.

33. Morin V, Pailhé R, Duval BR, Mader R, Cognault J, Rouchy R-C, et al. Gait analysis following medial opening-wedge high tibial osteotomy. Knee Surg Sports Traumatol Arthrosc. 2018;26:1838-44.

34. Faschingbauer M, Nelitz M, Urlaub S, Reichel H, Dornacher D. Return to work and sporting activities after high tibial osteotomy. Int Orthop. 2015;39: 1527-34.

35. Bastard C, Mirouse G, Potage D, Silbert H, Roubineau F, Hernigou P, et al, Return to sports and quality of life after high tibial osteotomy in patients under 60 years of age. Orthop Traumatol Surg Res. 2017;103:1189-91.

36. Webb M, Dewan V, Elson D. Functional results following high tibial osteotomy: a review of the literature. Eur J Orthop Surg Traumatol. 2018;28: 555-63.

37. Ihle C, Ateschrang A, Grünwald L, Stöckle U, Saier T, Schröter S. Healthrelated quality of life and clinical outcomes following medial open wedge high tibial osteotomy: a prospective study. BMC Musculoskelet Disord. 2016; 17. https://doi.org/10.1186/s12891-016-1076-x.

38. Maffulli N, Loppini M, Longo UG, Denaro V, Oliva F. Bovine xenograft locking Puddu plate versus tricalcium phosphate spacer non-locking Puddu plate in opening-wedge high tibial osteotomy: a prospective double-cohort study. Int Orthop. 2013:37:819-26.

39. Ekhtiari S, Haldane CE, de SAD, Simunovic N, Musahl V, Ayeni OR. Return to work and sport following high Tibial osteotomy: a systematic review. J Bone Jt Surg. 2016;98:1568-77.

40. Eberbach H, Mehl J, Feucht MJ, Bode G, Südkamp NP, Niemeyer P. Geometry of the Valgus knee: contradicting the dogma of a femoral-based deformity. Am J Sports Med. 2017;45:909-14.

\section{Publisher's Note}

Springer Nature remains neutral with regard to jurisdictional claims in published maps and institutional affiliations.

Ready to submit your research? Choose BMC and benefit from:

- fast, convenient online submission

- thorough peer review by experienced researchers in your field

- rapid publication on acceptance

- support for research data, including large and complex data types

- gold Open Access which fosters wider collaboration and increased citations

- maximum visibility for your research: over $100 \mathrm{M}$ website views per year

At $\mathrm{BMC}$, research is always in progress.

Learn more biomedcentral.com/submissions 